\title{
Water allocation and optimization of minor canal operation
}

\section{Hassan Ibrahim Mohamed ${ }^{1}$, Elsadig Elmahdi Ahmed ${ }^{1}$, Omran Musa Abbas ${ }^{1}$ and Abdel Moneim Elamin Mohamed ${ }^{2}$}

\author{
${ }^{1}$ Department of Agricultural Engineering, College of Agricultural Studies, Sudan University of \\ Science and Technology, Khartoum-Sudan \\ ${ }^{2}$ Department of Agricultural Engineering, Faculty of Agriculture, University of Khartoum- \\ Khartoum-Sudan
}

\begin{abstract}
In this study a mathematical simulation of canal operation is presented for optimizing water allocation within a multiple crop rotation canal. Zero-one linear programming algorithm was made for optimal flow regulation and to optimize irrigation water allocation and sequencing of different outlets in the irrigation canal under the constraints of fixed canal capacity and irrigation interval. The model was coded in a personal computer using Excel - visual basic application language (VBA) and designed to serve as a decision-making tool for operating an existing canal or for appropriate sizing of canal capacity (flow rate and cross-sectional area) of a new one.

The model is verified statistically in comparison with published models. The allocation model is applied to the real cases of wet and dry regions of Gezira Scheme - Sudan for sequencing canal outlets for the cases of early and peak season at Sunni Minor canal and Ugud Minor canal. The model sensitivity to changes in outlet inflow rate (working time per outlet) was made for the said two cases. This indicated the model capabilities to effectively provide a constant flow rate into the canal during the operating period, and consequently minimize the need to frequently adjust the settings of canal head regulator. The model capabilities to optimize water scheduling and allocation process can be used to save irrigation water during early stages of crop growth and to upgrade the operation of minor canals in the irrigated schemes in the Sudan.
\end{abstract}

Keywords: Integer optimization, canal water allocation, turnouts, scheduling, arranged demand irrigation.

\section{INTRODUCTION}

Many surface irrigation projects in most developing countries in general and in Sudan in particular perform at levels much below their potential in terms of crop productivity, water dependability, equity and efficiency. Thus frustrating the efforts to attain food supply for self-sufficiency and often threatening the economic justification on which these projects rest.

The reason is attributed to surface irrigation systems deterioration, management mode, change in project goals and the economic and social pressures. Certainly, the critical issue in improving performance of the canal system is the relative priority assigned to structural (such as canal lining, new flow control structures, land leveling) and non-structural (management, operation and maintenance) improvements measures. Thereafter, improvement efforts were focused on rehabilitating infrastructure and canal modeling works (hardware) which did not entirely solve all problems. To achieve appreciable progress it worth to supplement these programs with better management programs (software) which is expected to maximize returns against lower costs. Better management can be achieved via appropriate capacity building, better scheduling procedures, and sound canal operating rules.

Sound canal operation rules particularly under multicrop diversified cropping pattern is a difficult task. It requires establishment of procedures adaptable to the physical, socio-economic environment so as to accomplish canal system upgrade. However, methods of operating irrigation canal system include on demand, continuous and rotational method.

Rotational water distribution in irrigation projects is a common practice throughout the world. The supply is rotated among individual farmers in an outlet command, among outlets on distributor channel, and among different distributaries on a main canal. Until recently, a constant frequency, constant depth policy of water distribution has been followed. With this policy the operation schedule of the distribution system is calculated by knowing the irrigated area of 
each outlet. Once the area to be irrigated is known, the operation schedule for the distribution system is prepared and implemented throughout the season. During the last decade, however, in several places, the constant frequency constant depth policy has been replaced by the constant frequency variable depth policy. Frequency of irrigation in a command area is based on the soil-crop-climate conditions. With constant frequency variable depth, the depth of irrigation in each rotation is varied according to the crop needs, thus, a rotation system that closely matches demand has been introduced.

Water delivery and distribution can be classified as supply-oriented or demand based (Anwar, 2005). In a supply-based irrigation system, water is often distributed proportionally to the area of irrigation regardless of the actual demand of crops. Under a diversified cropping system the chances of over and under-irrigation are high because crops require different amounts of water at different growth stages when the supply to the main system is not sufficient, the flow in successive canals such as secondary and tertiary will be reduced proportionately. It often happens that water is monopolized by upstream users at the time of shortage and no water will be provided to tail-enders. It is rather the location of farm plots and power balance among water users which determine the priority and the amount of irrigation.

Under demand-based system, the amount of irrigation for each crop in each plot is defined by the water requirements and thus there could be little chance of over - and under - irrigation so far as the rule of water delivery is observed as determined. The constraints to introducing a demand-based are the requirements of data processing and the flexibility of the infrastructure to accommodate the fluctuating water demand. Demand-based water distribution has better prospects of satisfying timely, adequate and equal distribution and hence, achieving the objectives of irrigation.

The function of the main irrigation system is to supply irrigation water to the tertiary units according to the operational objectives. The general objective of main irrigation systems is to deliver water to the tertiary units with: sufficient head above the terrain (command), a reliable supply of water (water arrives when it is supposed to and in proper quantities and flow rates), in an assured way (i.e. chance of failure of $20 \%$ ) and flexible supply of water (meeting the changing water needs for irrigation).
Worldwide computer simulation of irrigation systems has been attempted by several workers for determining crop water allocation. In accordance with this Anderson and Maass (1971) developed a simulation procedure to study the effect of water supply and operation rules on the production and income of irrigated farms. A soil balance approach was adopted by Rajput and Michael (1989) for development of an integrated canal scheduling model. Brower and Buchheimn, (1982) at the U.S Department of Interior Bureau of Reclamation (USBR) have developed programs to assist in irrigation management. Many researcher (Bellostass, 1994; Matanga and Marino, 1979a, 1979b and Zhenmin 1994), developed models for water allocation between different crops based on linear programming for maximization of economic benefit. Many of these models were developed for specific conditions and cannot be used directly in all irrigation systems. In addition, those models employ the economic evaluation as the only decision criteria. The economic decision is based on single prices. Estimate for future status from the current values and price profile through season is unknown.

A linear programming (LP) models emphasize one or more particularities concerning the spatial scale, time horizon, the specificity of the decision variables and the constraint or any element entering in the equations. Solving the problem requires very careful preparation of the equations, while the complex programming and debugging (tracking down and fixing program bugs to spot problems and make the programming more rewarding) were time consuming.

Water allocation has received considerable attention in the recent past by the scientific community. Many optimization techniques available in literature which are made for allocation of scarce water, employed linear programming techniques (Bellostass,1994 and Yoo and Busch,1985).This is because linear programming (LP) is an excellent tool for solving optimization problems. The capacity of a demand system is a function of the probability of the number of users simultaneously using the system. The authoritative work on this problem by Clement (1966) used the probability of the system capacity being exceeded or the system being busy when a user requests the service to relate to the service required. Most work on capacity for demand system is based on pressurized systems (Clement, 1966, Monserrat et al. 2004). Suryavanshi and Reddy (1986) published a paper on the operation schedule of an irrigation distribution system in which the constant- 
frequency variable-depth method of water delivery is discussed. The problem of clustering and sequencing outlets on a distributary channel to determine required quantity of water is described and formulated as a zero-one linear programming problem.

Wang et al (1994) tried to re-solve the scheduling and allocation problem described by Suryavanshi and Reddy (1986) by modifying the objective function. The modification is made by taking one collective cost (for construction of a new canal or cost of water conveyance loss in an old canal) of the group of outlets working together rather than considering the cost of each individual outlet. In 2005 Anwar et al reformulated Suryavanshi and Reddy (1986) model by using the classical machine scheduling terms of earliness and tardiness and introduced the index of relative timeliness so as to investigate whether the tertiary unit, given its current capacity, can be operated on an arranged demand basis. However, start times are generated as uniformly distributed random number integers over the irrigation interval. This may not be strictly speaking true.

As stated by Anwar et al (2005) themselves the model in its current form cannot be used for developing guidelines for designing of a new canal.

In Sudan major schemes were designed following the Gezira design. The Minor canals of the Gezira were designed on rotational basis for a mono-cropping pattern, cotton being the main crop. Half the number of outlet pipes per Minor was operated at the same time for seven days on, and seven days off with constant irrigation interval of fourteen days.

Due to the intensification and diversification the classical operation model is no longer valid. Some of the impacts of intensification and diversification can be summarized in low water course inflow (Abu xx), longer irrigation intervals, longer operating time, unattended irrigation, lower canal maintenance levels, and hence lower canal carrying capacity.

Due to the privatization policy where farmers are given free choice of crop to grow the discharges through the outlets and the areas irrigated under the outlets often differ, but the discharge capacity of each outlet is assumed constant. Crops grown on individual farms within each irrigation unit (Number) are also different as are their irrigation requirements in each rotation. During the actual operation of irrigation, ever changing cropping patterns, irrigation requirements and technologies the actual water demand and the time of delivery among outlets are dramatically varied, making it necessary to reschedule the water deliveries before each rotation. The operational schedules thus need to be readjusted as the allowed incoming flow rate and/or inflow period changes. Hence, it is necessary to vary the running time of each outlet during each rotation. Once the running time of each outlet is estimated, the operation schedule of the outlets, which determines the inflow hydrograph into the distributaries, must be specified. At this stage it must be decided whether to operate all the outlets simultaneously or in sequence. However, irrigating with all the outlets simultaneously open would necessitate a larger canal capacity, which is economically undesirable (large flow rate that may exceed canal capacity). Running the outlets in sequence would allow the use of a smaller canal ,which is economically desirable, but the total running time might exceed the time available for that part of the rotation (economically undesirable). Therefore, the optimal operation schedule is the one that would supply water to all outlets within the time available for the rotation using the most economic canal capacity. In an existing irrigation project, the capacity of the distributary channel (Abu $\mathrm{xx}$ ) is already fixed. Hence, optimal operation scheduling only deals with sequencing the outlets so that within the given system capacity, the total running time of the outlets is less than the available rotation time. The inflow hydrograph into the distributary channel (Minor) must match the opening and closing sequence of the outlets or vice versa. Otherwise, significant amounts of water may be wasted. The optimal operation schedule of the outlets and the inflow hydrograph into the distributary channel can be prepared manually, but in a large irrigation project with many outlets and distribution channels the procedure is time-consuming.

Guided by this background the specific objectives of this study are two folds: to develop a mathematical model for simulation of canal operation, for purpose of preparing operation plan well before the start of any rotation, and to verify and apply the developed plan under field conditions of the Sudan Gezira Scheme.

\section{MODEL DEVELOPMENT}

Conceptual framework: The optimization model for minor canal operation is an integer linear programming model. The minor is assumed to be operated on rotational flow basis between distributor outlets (Abu XXs). In formulating the water 
distribution problem in a mathematical form, the canal capacity is assumed to be fixed and it is assumed to serve a number of live outlets. The maximum number of live outlets in the model is 14 outlets but with some simple modification the model can accept up to 28 live outlets. The minor is thus supposed to contain a number of sub-routes each with a design discharge equivalent to that of the supplied outlet. Therefore, the total capacity of the minor is equal to the sum of the capacities of the sub-routes contained. Each outlet is assumed to run with a user defined fixed discharge.

The operating cost of each live outlet and hence the operating cost per minor is assumed to be a function of the operating time and expressed as penalty factor. However, the penalty factor is analogous to the multimachine schedule solution that allows scheduling of a number of irrigation events according to their target start times (Anwar and Clarke, 2001).

During the operation each live outlet once open remains functioning until it satisfies the demand of its cultivated area. The numbers of outlets working simultaneously are determined by the canal capacity and the average discharge of the outlets. The Model limitation includes:

-The program requires the installation of the optimization unit (What's Best) which works within the excel medium.

-The maximum number of integers is 200 which limit the maximum capacity of the program to twenty eight working outlets.

-The program offers only four scenarios viz; eight, ten, twelve and fourteen working outlets. However with a simple modification the program can accept up to twenty eight working outlets.

Program structure, technique and style: The program is interactive and composed of sub modules, where the user is prompt to enter relevant data for the sub modules via a sequence of button driven menus. The user has the option to execute each submodule separately or the whole model as one unit. In this study built in data were made available for crop type, growth stages and crop factor for mid and late stages from FAO tables (1998) alternatively the user has the option of using his own crop stages figures when available. Data is entered in special cells or text boxes which are linked to other cells through data processing equations. Data entry is a step by step process in specifically designed interfaces for each sub-module.

Relevant guiding notes are given where necessary to help the user in program use. For data correction excel engine facilities are used. The user is always given the freedom to use site specific data or use built in data when available with the necessary adjustments. Program style of links between cells and work sheets is designed in order to build the modular form of program and reach efficient solution.

Program logic, flow chart, and Data entry: The program is composed of an introductory interface and a main menu form. It derives through sub-modules distributed over the spread sheets. The main menu controls the sequence of all program operations. Spread sheets are either visible input interfaces or hidden processing sheets. Visible input interfaces receive input data subjected to them to the necessary conversions and direct them to hidden processing sheets where all the necessary processes are done. Data will then appear as output data in an appropriate visible form. (Program flow chart: Fig. 1)

The user needs to enter input data in tabular format directly from the screen. Alternatively built in FAO published data can be used for estimating the suitable values if no local data is available. The format of the needed data is explained and described in the following sections with their respective modules.

Optimization techniques: The objective function is expressed in terms of the decision variables Xij. Assuming that it is an existing minor canal the objective is the operational schedule that minimizes the cost of operation of the distributary (Abu XX) and consequently the minor canal. The objective function is expressed as:-

$$
\operatorname{Min} \sum_{i j}^{n m} C_{i} X_{i j}
$$

Where: $(n=m)$ and $\mathrm{n}$ is number of routes (groups); and $\mathrm{m}$ is the number of outlets on the minor and $\mathrm{Ci}$ is the operation cost penalty factor of the outlet via its respective route. Initially $n$ is assumed to be equal to $\mathrm{m}$. The operating cost penalty factor is introduced so as to minimize the total operation cost and to assure that once the outlet is open it remains on for the coming working days. By virtue of the penalty each outlet seeks to start operation as early as possible and tries to avoid opening twice because the second opening will incur a penalty. Hence the theoretically economic condition is to open all outlets at one time but the canal capacity is not sufficient to supply all outlet at one time. 


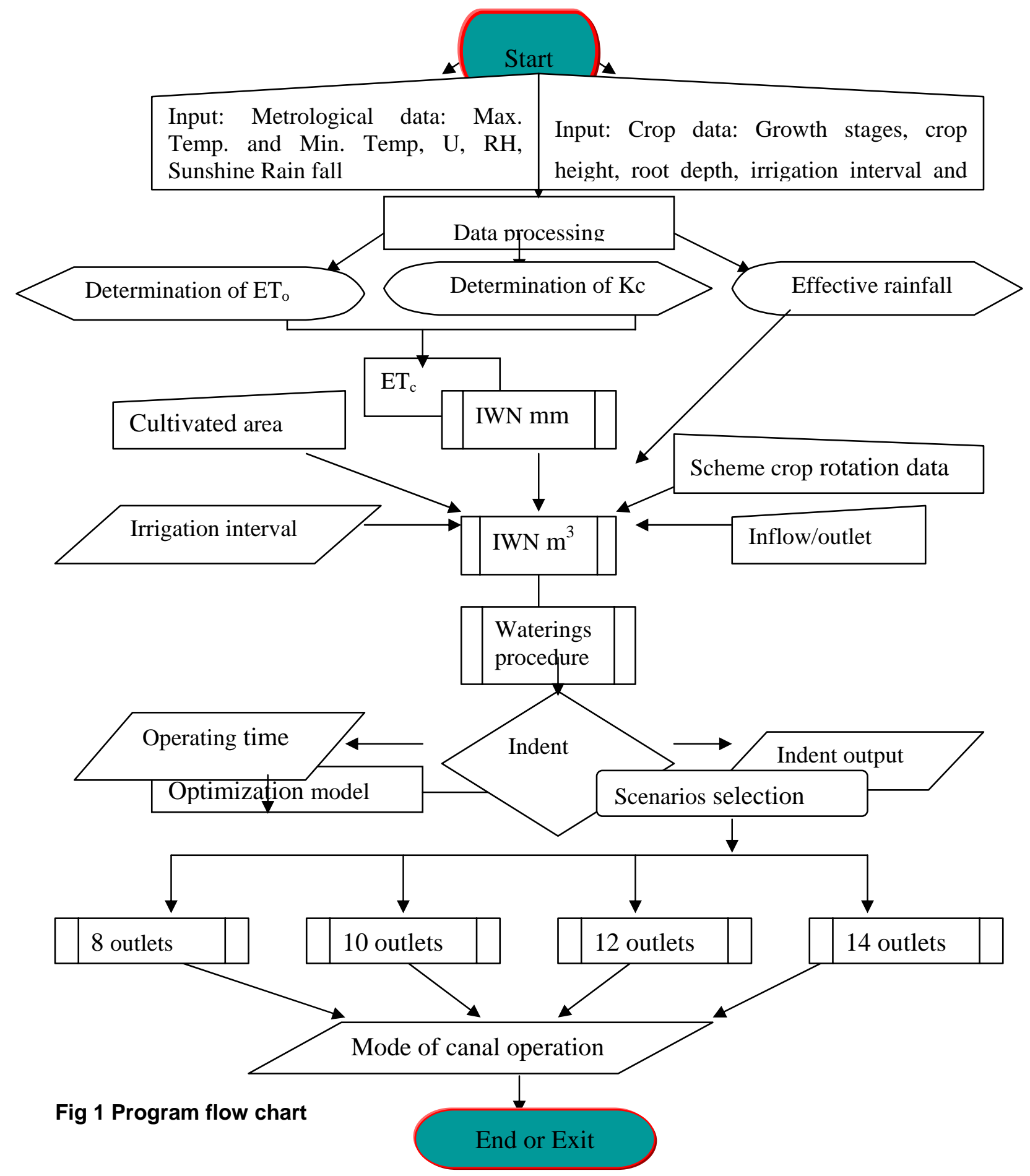

To schedule the operation of the outlets, the system is subject to some constraints and preferences that need to be satisfied these constraints are specified as follows:-
1. The total running time of the outlets in any group running sequentially should not exceed the irrigation interval (running time). If $\mathrm{a}_{\mathrm{j}}$ represent the running time of outlet $j$ the $n$ constraints are stated as:- 


$$
\operatorname{Min} \sum_{\mathrm{ij}}^{n m_{j}} \mathrm{a}_{\mathrm{ij}} \leq \mathrm{D}
$$

Where $a_{j}$ is the running time of outlet $j$ (days) and $D$ is the total time available for irrigation during a given rotation of each distributary channel (Abu XX) in days.

2. The binary constraint states that a value of one is assigned to an outlet when it is open while a value of zero is assigned to it when it is closed. Hence:-

$$
\begin{aligned}
& X_{i j}=I \text { when outlet } j \text { is open } \\
& X_{i j}=0 \text { when outlet } j \text { is closed }
\end{aligned}
$$

In order to schedule the sequence of operating the outlet within the limits of the existing canal capacity the number of open outlets at any one time should not exceed the maximum number of outlets (via their respective routes) the canal can satisfy.

This is stated mathematically as follows:-

$$
\sum^{n m}{ }_{i j} X_{i j} \leq \text { canal capacity }
$$

Where: canal capacity represents the maximum number of outlets (routes) that can work at any one time in the minor canal. i.e. Minor discharge divided by average outlet discharge.

Or $\sum_{i j}^{n m_{i}} \mathrm{q}_{\mathrm{i}} \leq \mathrm{Q}_{\mathrm{t}}$

Where: $m=$ the number of open outlets (i) at one time, $\mathrm{q}_{\mathrm{i}}=$ inflow rate for outlet (i) and $\mathrm{Q}_{\mathrm{t}}=$ Canal capacityMATERIALS AND METHODS

The study area: The Gezira scheme is one of the largest irrigation schemes in the world (Fig. 2). It is still the largest and most important agricultural scheme in Sudan. Its management is shared by the Sudan Gezira Board (SGB) and the Ministry of Irrigation (MI). SGB is responsible for the agricultural operations while MI looks after the irrigation network. The scheme covers 880,000 ha of the plains between the Blue and White Niles south of Khartoum. Irrigation water is fed by gravity from Sennar Dam through two main canals. Their combined design capacity is of about 30 million cubic meters per day. These lead to 860 kilometers of Branch and Major canals and 7500 kilometers of Minor canals. Water is fed from the Minor canals through field outlet pipes (FOPs) to the field water courses (Abu XXs). Each Abu XX used to feed nine lateral water courses (Abu VIs). Now it generally feeds 19 (Abu VIs) each of which commands about half the area commanded by the old Abu VI (Ahmed et al, 1996).
The main crops historically grown in the scheme are extra long and medium staple cotton, wheat and sorghum or groundnuts. Vegetables are sometimes grown on the first fields of the groundnut/sorghum area. Forests and permanent gardens are also grown in some locations, but comprise a small area compared to the total cropped area. The main crops are grown in four course rotations. Managil area is a part of the Gezira scheme, and follows a three years course rotation. Recently, the farmers are given the freedom to select the type of crop to cultivate as dictated by market force.

The system of irrigation in the canal network higher than the Minor is known to be continuous flow system. The Night Storage System (NSS) is supposed to be practiced at the Minor canals and the field water courses. The main idea behind (NSS) is to use the Minor canals as conveyors during the day time and as reservoirs by night. All intermediate regulator gates along the Minors and all FOPs are supposed to be closed at night. Water would thus be stored in the Minor canal to the night storage level. The intermediate regulators should be opened at 6 a.m. next morning together with the FOPs scheduled for irrigation that day. The main features of this system are to overcome difficulties of irrigation by night and keep the high head and so high discharges to Abu XXs during the day time. As per design each Abu XX should irrigate for one week and be kept closed for the next week. Average design flow through the field outlet pipe is about $5000 \mathrm{~m}^{3}$ per day (about $116 \mathrm{l} / \mathrm{sec}$ ) and that through Abu VI is expected to be around 60 $\mathrm{l} / \mathrm{sec}$ and $30 \mathrm{l} / \mathrm{sec}$ depending on whether the plots are nine or eighteen in number. In practice the flow rate and time of operation of a water course and irrigation interval are different (Ahmed et al, 1986).

As given by Farbrother (1975) and Ahmed et al. (1986) the Sudan Gezira Board shoulders the responsibility of the day-to-day operation of the Minor canals. In 2005 the daily water management in the Minor canals is transferred to water user associations.

The Block Inspector and his staff of one to three Khaffirs per Minor now acts on behalf of the water user association. After receiving the continuous 24-hr supply at the head of each Minor from the major in response to their indent, the inspector and his staff have to operate the regulators between successive reaches in such a way that the distribution from head to tail of the Minor is as fair and equitable as possible to all tenants, irrespective of their location on the Minor. 
The water Khaffirs have only two variables with which to ensure fair distribution between reaches: either control of the number of FOPs open simultaneously or the relative openings of the regulator gates.

The number of FOPs required to be open has changed completely since intensification and diversification in recent years. Although the number of FOPs open has been given above as one of the variables traditionally under the control of water Khaffirs, this is now not effective in practice. Moreover, the timing of the opening of FOPs on which recommended interval depended, is not now imposed by schedule from above, but originates, instead, from below, depending on the tenants judgment of the requirements of their crops. Since intensification, the situation is entirely different from the traditional management, under which the number of open FOPs was arranged by the inspector and Khaffirs solely to achieve the recommended timing of the basin "Angaya" system and giving priority to cotton numbers.

The increased number of FOPs now open has imposed the change of the method of operation of the gates of the successive regulators so that the distribution to downstream reaches still remains fair. The Chaffers judge the opening and closing of the Minor regulators on a scale of screws (the number of turns of thread above the frame nut).

The traditional system of complete shutting of regulators at night is no longer valid, because operation of Minor has moved almost entirely to continuous-flow system. Instead the regulators are left as long as possible at the openings that are found in practice to give comparable supply heads in the immediate reaches above and below, irrespective of where they might be relative to the FSL.

The shifting of the system from night-storage to continuous-flow has lead to the rise of many complaints. The irrigation engineers complain that they are no longer able to maintain the traditional supply levels expected. The tenants complain that water is not always available when they need it. As such, the working level and the stable head in the Minor are not yet fully defined. The present water allocation method of Optimum Supply Level (OSL) made to a chive stable water level in the Minor, although appreciated, does not mean that the present operation of the Minor as continuous flow canal cannot be further improved.

Under present field method of unattended night watering, heads unexpectedly higher than optimum can disrupt the smooth progress of irrigation with far more serious agricultural consequences than suboptimal level heads. Flooding of low areas, and waste of water to roads or drains through breaks along 'the tangent boundaries of numbers affect yield and efficiency of water use.

It could be concluded that a great deal of applied research supported by mathematical modeling and field extension is required to establish a sound basis for indenting and sequence of opening of FOPs in the future.

The study sites: The data for model verification is taken from the distributary (Minor) No. 3, Meena Branch of the Kukadki Irrigation project, Mahrashtra, India, first described by Suryavanshi and Reddy (1986) (Table 3). There are eight outlets on the channel, each with a constant discharge of $30 \mathrm{l} / \mathrm{sec}$. The duration for each of these outlets, was estimated by Suryavanshi and Reddy (1986) based on estimates of crop water requirements using the Modified Penman method, field application efficiency of $70 \%$ and losses of $20 \%$ per $1000 \mathrm{~m}$ of field channel. The Distributary was in operation for six days.

(Irrigation interval = six days, and outlet inflow rate $=30 \mathrm{l} / \mathrm{s})$ )

The field data for model application was collected from two sites within Gezira scheme as case studies Sunni and Ugud Minor canals:

(i) Sunni Minor canal: It is a short canal which is located in Tayba Block at Massalamia Group and represents the center of Gezira. El Sunni Minor consists of sixteen water courses (FOPs) with a total area of 354 hectares. A well head regulator with intermediate night storage weir (at kilo 2) divides the Minor into two reaches. The site was chosen because it is the site of the Gezira rehabilitation program pilot farm, also because it is the site used in the past to the study of the scheme crop water requirement. Six outlets are closed and left as fallow (without crops). Crops grown are cotton (2-outlets), groundnut (one outlets), sorghum (3- outlets), wheat (4- outlets) and .Field data was collected during watering number twelve from six working outlets (2cotton and 4-wheat). Two scenarios of outlet inflow rate were taken: the design inflow rate $(116.0 \mathrm{l} / \mathrm{s})$ and the actual flow rate of $81.0 \mathrm{l} / \mathrm{s}$.

Watering time for each outlet (FOP) is determined by considering the water requirement of the crop grown, actual cultivated area, 14-day irrigation interval, and FOP discharge rate (Table4).

(ii) Ugud Minor canal: situated in Laota Office and represent the northern parts of the Gezira Scheme. 
The canal extends to a length of $8.4 \mathrm{Km}$. It is commands 30 outlets (numbers) distributed over three reaches and in the order of;(1 to 10), 78 (11 to 16) and (17 to 30 outlets). The outlets in the Minor thirty involve permanent gates with design inflow rate of $116.0 \mathrm{l} / \mathrm{s}$ per each outlet and the Minor serves crops in about 703 hectares. Crops cultivated include cotton (5-outlets), groundnut (5-outlets), sorghum (5outlets), vegetables (2-outlets), and 12-oulets are left fallow. Data is monitored during summer time at watering number six is taken from 10 turnouts (cotton 5 FOPs, and Groundnut 5 FOPs). Field data for winter season is collected from watering number ten over thirteen outlets (cotton 5 FOPs, Sorghum 6 FOPs, and vegetables 2 FOPs). Watering times for irrigation number six and ten is depicted in table 5 .

Data collection: Meteorological data of maximum and minimum temperature, rainfall, wind speed, bright sunshine hours and relative humidity were taken for the period of 30 years $(1961$ - 1990) as reported by Wad Medani Meteorological Station. The agricultural data: was obtained from the corresponding Block Inspectors. These data include type and areas of crop grown in each FOP, dates of planting, length of the growing stages, rooting depth and water indents for season 2003/2004. Other data includes number of live FOPs, discharge, and irrigation time for each turnout.

RESULTS AND DISCUSSIONS

Verification of the Canal Operation Model: Table 4 shows the output of the operating schedule of outlets given by Suryavanshi and Reddy (1985). There (1985) numerical solution indicates that there are four groups of outlets watering simultaneously. This requires a canal capacity of $120 \mathrm{l} / \mathrm{s}$. The percentage of actual time utilized in watering compared to the irrigation interval is $84 \%$. If these outlets are irrigated by turn they require 14.11 days. The Suryavanshi and Reddy (1985) allocation model require 5.05 days to irrigate all fields which is equivalent to $36 \%$ of the total available time. The required canal capacity estimated by Suryavanshi and Reddy (1985) allocation model is $(120 \mathrm{l} / \mathrm{s})$ which is half of the actually used capacity ( $240 \mathrm{l} / \mathrm{s})$.

Table 1 Canal and irrigation events Data of Meena Branch Canal -The Kukadi Irrigation Project in Maharashtra, India (Suryavanshi and Reddy, 1986)

\begin{tabular}{|l|l|l|l|l|l|l|l|l|l|}
\hline Outlet Number & 1 & 2 & 3 & 4 & 5 & 6 & 7 & 8 & Total Duration \\
\hline Duration(days) & 0.80 & 2.13 & 2.4 & 1.72 & 2.05 & 2.43 & 2.05 & 2.50 & 16.08 \\
\hline
\end{tabular}

Table 2 Watering periods for each working outlet during watering number 12 (Time of peak demand) in Suni Minor Canal using actual discharge $(81 \mathrm{l} / \mathrm{s})$ and the design discharge $(116 \mathrm{l} / \mathrm{s})$ :

\begin{tabular}{|l|c|c|c|c|c|c|c|}
\hline Outlet No & 1 & 2 & 3 & 4 & 5 & 6 & Total days \\
\hline $\begin{array}{l}\text { Watering duration (days) } \\
\text { Outlet discharge=5000 m^3/day }\end{array}$ & 6.3 & 6.3 & 6.7 & 7.3 & 3.2 & 2.8 & 32.6 \\
\hline $\begin{array}{l}\text { Watering duration (days) } \\
\text { Outlet discharge=3500 m^3/day }\end{array}$ & 9.0 & 9.0 & 8.1 & 10.4 & 6.4 & 4.0 & 46.9 \\
\hline
\end{tabular}

Table 3 Watering periods(days) for irrigation number six and ten in Lugud Canal using Outlet discharge of 5000 $\mathrm{m}^{3}$ /day

\begin{tabular}{|l|c|c|c|c|c|c|c|c|c|c|c|c|c|c|}
\hline Outlet No & 1 & 2 & 3 & 4 & 5 & 6 & 7 & 8 & 9 & 10 & 11 & 12 & 13 & $\begin{array}{c}\text { Total } \\
\text { days }\end{array}$ \\
\hline $\begin{array}{l}\text { Watering duration } \\
\text { Early season Watering No } \\
6\end{array}$ & 5.4 & 5.4 & 3.4 & 3.4 & 2.8 & 2.8 & 0.7 & 0.8 & 0.9 & 0.9 & 0 & 0 & 0 & 26.5 \\
\hline $\begin{array}{l}\text { Watering duration } \\
\text { Late season Watering No } \\
10\end{array}$ & 7.3 & 7.3 & 7.1 & 7.1 & 6.9 & 5.0 & 5.0 & 6.1 & 6.1 & 6.7 & 6.7 & 4.7 & 4.7 & 80.7 \\
\hline
\end{tabular}


Agric. Biol. J. N. Am., 2010, 1(5): 1031-1043

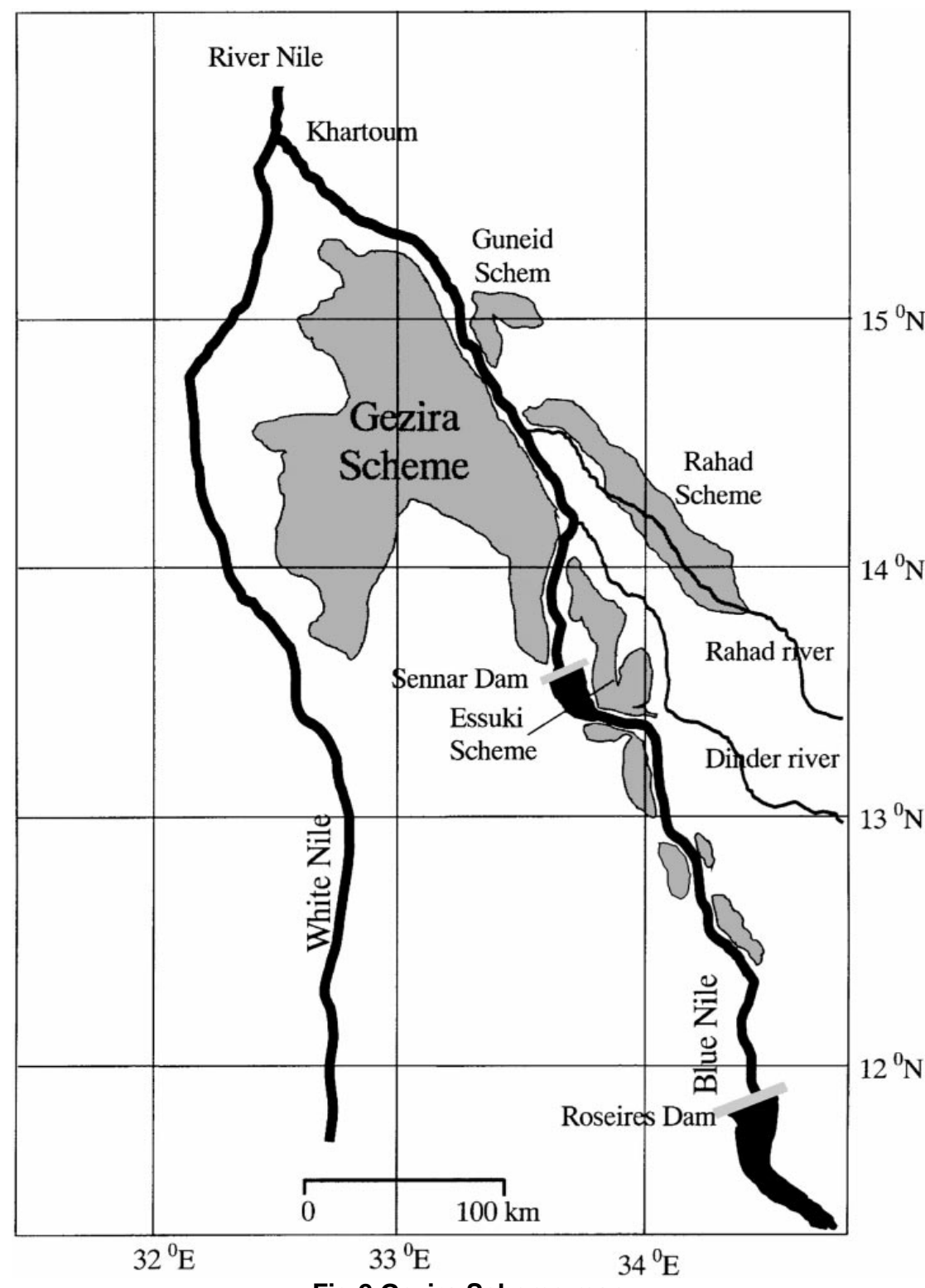

Fig 2 Gezira Scheme map

The data of Suryavanshi and Reddy (1985) was formulated as input of $8^{\star} 8$ scenario into the model as depicted in table 3 . The model solution succeeded in reducing the number of groups working simultaneously to only three groups, which results in a reduced canal capacity of $90 \mathrm{l} / \mathrm{s}$ and consequently cuts down construction and operating cost of the canal by $63 \%$. Comparison of the outputs of the developed model with that of Anwar et al. (2005) is given in Table 5. Although the outlets grouping of these two models are different, the two model results are typical with respect to reduction of canal capacity and utilization of operating times (Table5).

\section{Application of Canal Operation Model:}

a--The Case of Sunni Canal: The developed model was applied during the peak season at watering twelve in Sunni canal by formulating the watering time data of each outlet in matrix format. The results show that the model gave a feasible operating schedule and maintain the design and operating rules of the canal system when the outlet design discharge is maintained. This can be visualized in table 6 by finishing the irrigation within the design irrigation time and by reducing the canal capacity into half. 
Table 4 Analysis of Suryavanshi and Reddy (1986) Model (using 30 l/s outlet discharge and 6-days interval):

\begin{tabular}{|c|c|c|c|c|}
\hline Group & Outlets opening groups & \multicolumn{3}{|c|}{ Duration (days) } \\
\hline 1 & 1,4 and 8 & \multicolumn{3}{|c|}{5.05} \\
\hline 2 & 2 and5 & \multicolumn{3}{|c|}{4.18} \\
\hline 3 & 3 and 7 & \multicolumn{3}{|c|}{2.45} \\
\hline 4 & 6 & \multicolumn{3}{|c|}{2.43} \\
\hline & Total & \multicolumn{3}{|c|}{14.11} \\
\hline & $\begin{array}{l}\% \text { of utilization of } 14 \text { day interval } \\
\text { time }\end{array}$ & $(5.05 / 6)=$ & 84 & $\%$ \\
\hline & $\begin{array}{l}\text { Time saving (compared to by } \\
\text { turn) }\end{array}$ & $(5.05 / 14.11)=$ & 36 & $\%$ \\
\hline \multirow[t]{3}{*}{ Canal Capacity(I/sec) } & & $4 \times 30$ & 120 & $\mathrm{l} / \mathrm{s}$ \\
\hline & $\begin{array}{l}\text { Capacity utilization (compared to } \\
1508 \mathrm{l} / \mathrm{s} \text { by turn) }\end{array}$ & $(120 / 240)=$ & 50 & $\%$ \\
\hline & $\begin{array}{l}\text { Capacity saving (compared to } \\
\text { by turn of " } 8 \times 30 \mathrm{l} / \mathrm{s} ")\end{array}$ & & 50 & $\%$ \\
\hline
\end{tabular}

Table 5 Analysis of Suryavanshi and Reddy (1986) Data (using 30 l/s outlet discharge and 6-days interval) by Anwar et al. (2005) and the developed model:

A / Results o Anwar et al. (2005) model (using 30 l/s outlet discharge and 6-days interval)

\begin{tabular}{|c|c|c|c|c|}
\hline Group & Outlets opening groups & Duration (days) & & \\
\hline 1 & $8,6,1$ & 5.7 & & \\
\hline 2 & $5,4,2$ & 5.9 & & \\
\hline \multirow[t]{4}{*}{3} & 7,3 & 4.5 & & \\
\hline & Total & 16.1 & & \\
\hline & $\begin{array}{l}\% \text { of utilization of } 14 \text { day interval } \\
\text { time }\end{array}$ & $(5.9 / 6)=$ & 98 & $\%$ \\
\hline & $\begin{array}{l}\text { Time saving (compared to by } \\
\text { turn) }\end{array}$ & $(5.9 / 14.11)=$ & 36 & $\%$ \\
\hline \multirow[t]{3}{*}{ Canal Capacity(I/sec) } & & $3 \times 30$ & 90 & $\mathrm{l} / \mathrm{s}$ \\
\hline & $\begin{array}{l}\text { Capacity utilization (compared to } \\
1508 \mathrm{l} / \mathrm{s} \text { by turn) }\end{array}$ & $(90 / 240)=$ & 38 & $\%$ \\
\hline & $\begin{array}{l}\text { Capacity saving (compared to by } \\
\text { turn of " } 8 \times 30 \mathrm{l} / \mathrm{s} \text { ") }\end{array}$ & & 63 & $\%$ \\
\hline
\end{tabular}

B /Results of the Developed Model Solution (2009) (using $30 \mathrm{l} / \mathrm{s}$ outlet discharge and 6-days interval)

\begin{tabular}{|c|c|c|c|c|}
\hline Group & Outlets opening groups & \multicolumn{3}{|l|}{ Duration (days) } \\
\hline 1 & $2,4,7$ & \multicolumn{3}{|l|}{5.9} \\
\hline 2 & $1,3,5$ & \multicolumn{3}{|l|}{5.25} \\
\hline 3 & 6,8 & \multicolumn{3}{|l|}{4.93} \\
\hline & Total & \multicolumn{3}{|l|}{16.08} \\
\hline & $\begin{array}{l}\% \text { of utilization of } 14 \text { day interval } \\
\text { time }\end{array}$ & $(5.9 / 6)=$ & 98 & $\%$ \\
\hline & $\begin{array}{l}\text { Time saving (compared to by } \\
\text { turn) }\end{array}$ & $(5.9 / 14.11)=$ & 36 & $\%$ \\
\hline \multirow[t]{3}{*}{ Canal Capacity(I/sec) } & & $3 \times 30$ & 90 & l/s \\
\hline & $\begin{array}{l}\text { Capacity utilization (compared to } \\
1508 \mathrm{l} / \mathrm{s} \text { by turn) }\end{array}$ & $(90 / 240)=$ & 38 & $\%$ \\
\hline & $\begin{array}{l}\text { Capacity saving (compared to by } \\
\text { turn of " } 8 \times 30 \mathrm{l} / \mathrm{s} \text { ") }\end{array}$ & & 63 & $\%$ \\
\hline
\end{tabular}


Table 6 Results of the Developed Model Solution (2009) for the case of Suni Canal at watering twelve using the design discharge and 14-days irrigation interval

Suni Canal, Watering No.12, Outlet inflow=5000m^3/day, Peak demand

\begin{tabular}{|c|c|c|c|c|}
\hline Group & Outlets opening groups & \multicolumn{3}{|c|}{ Total Duration (days) } \\
\hline 1 & $4,5,6$ & \multicolumn{3}{|c|}{13.3} \\
\hline 2 & 1,3 & \multicolumn{3}{|c|}{12.0} \\
\hline 3 & 2 & \multicolumn{3}{|c|}{6.3} \\
\hline & Total & \multicolumn{3}{|c|}{31.6} \\
\hline & $\%$ of utilization of 14 day interval time & $(13.3 / 14)=$ & 95 & $\%$ \\
\hline & Time saving (compared to by turn) & $(13.3 / 32.6)=$ & 41 & $\%$ \\
\hline Canal & ity(l/sec) & $3 \times 116$ & 348 & $1 / \mathrm{s}$ \\
\hline & Capacity utilization (compared to by turn)(6 x $116 \mathrm{l} / \mathrm{s})$ & $(348 / 696)=$ & 50 & $\%$ \\
\hline & Capacity saving (compared to by turn)( & & 50 & $\%$ \\
\hline
\end{tabular}

In actual field operating conditions in Suni Minor the inflow of each outlet drops down to 3500m3/day (81.0 l/s) as confirmed by Farbrother, 1975 and Ahmad, 1999.When operating the canal under the reduced outlet discharge the model generate a feasible solution. The results given in Table 7 shows that there is slight increase in both actual operating time and canal capacity compared to the case of running each outlet at the design discharge. As given in table 7 the model application indicate that a saving of $33 \%$ of the maximum canal capacity can be achieved for this case of reduced outlet discharge.

\section{(ii)The Case of Ugud Canal:}

a- Early Season (watering 6): At early season (watering 6) watering time data is formulated in a matrix format to be amenable for solution by the model optimization algorithm. Output operating schedule is given in table 8 for watering number six using an outlet design discharge of $116 \mathrm{l} / \mathrm{s}$, and fourteen day irrigation interval. The schedule indicate that it is possible to operate the canal using only two groups which results in $80 \%$ saving in the canal maximum capacity. However, this model computed capacity is lower than the classical design capacity of operating the canal at half number of outlet pipes running at one time $(580 \mathrm{l} / \mathrm{s})$ by $40 \%$.

b- Peak season (watering 10): At peak season (watering 10) where the number of live outlets increased to thirteen in Ugud the canal operating time data was formulated in matrix format ( $7 \times 13)$, and solved by the model. The operating schedule is given in table 9 using an outlet inflow rate of $5000 \mathrm{~m}^{3} /$ day . The generated schedule indicates that it is possible to operate the Minor canal at $45 \%$ its maximum capacity and it is not possible to adopt blindly the orthodox rule of running only half the number of live outlets at one time (two groups only).

Table 7 Results of the Developed Model Solution (2009) for the case of Suni Canal at watering twelve using the actual outlet discharge (81 I/s) and 14-days irrigation interval

\begin{tabular}{|c|c|c|c|c|}
\hline Group & Outlets opening groups & \multicolumn{3}{|c|}{ Total Duration (days) } \\
\hline 1 & 2,5 & \multicolumn{3}{|c|}{13.6} \\
\hline 2 & 1,6 & \multicolumn{3}{|c|}{13} \\
\hline 3 & 4 & \multicolumn{3}{|c|}{10.4} \\
\hline 4 & 3 & \multicolumn{3}{|c|}{8.1} \\
\hline & Total & \multicolumn{3}{|c|}{45.1} \\
\hline & $\%$ of utilization of 14 day interval time & $(13.6 / 14)=$ & 97 & $\%$ \\
\hline & Time saving (compared to by turn) & $(13.6 / 32.6)=$ & 41 & $\%$ \\
\hline Canal & $\operatorname{ty}(\mathrm{l} / \mathrm{sec})$ & $4 \times 81$ & 324 & $\mathrm{l} / \mathrm{s}$ \\
\hline & Capacity utilization (compared to by turn) $(6 \times 81 \mathrm{l} / \mathrm{s})$ & $(324 / 486)=$ & 67 & $\%$ \\
\hline & Capacity saving (compared to by turn)(486 l/s) & & 33 & $\%$ \\
\hline
\end{tabular}


Table 8 Results of the Developed Model Solution (2009) for the case of Lugud Canal at watering six using the design outlet discharge (116 l/s) and 14-days irrigation interval

\begin{tabular}{|c|c|c|c|c|}
\hline Group & Outlets opening groups & \multicolumn{3}{|c|}{ Tota Duration (days) } \\
\hline 1 & $1,2,7,8,9$ & \multicolumn{3}{|c|}{13.1} \\
\hline 2 & $3,4,5,6,10$ & \multicolumn{3}{|c|}{13.3} \\
\hline & Total & \multicolumn{3}{|c|}{26.4} \\
\hline & $\%$ of utilization of 14 day interval time & $(13.3 / 14)=$ & 95 & $\%$ \\
\hline & Time saving (compared to by turn) & $(13.3 / 26.4)=$ & 41 & $\%$ \\
\hline Canal & $\operatorname{city}(\mathrm{l} / \mathrm{sec})$ & $2 \times 116$ & 232 & $\mathrm{l} / \mathrm{s}$ \\
\hline & Capacity utilization (compared to"10x116" by turn) & $(232 / 1160)=$ & 20 & $\%$ \\
\hline & Capacity saving (compared to by turn of $1160 \mathrm{l} / \mathrm{s}$ ) & & 80 & $\%$ \\
\hline
\end{tabular}

Table 9 Results of the Developed Model Solution (2009) for the case of Lugud Canal at watering ten using the design outlet discharge (116 I/s) and 14-days irrigation interval

\begin{tabular}{|c|c|c|c|c|}
\hline Group & Outlets opening groups & \multicolumn{3}{|c|}{ Total Duration (days) } \\
\hline 1 & 12,13 & \multicolumn{3}{|c|}{9.4} \\
\hline 2 & 6,9 & \multicolumn{3}{|c|}{11.1} \\
\hline 3 & 3,10 & \multicolumn{3}{|c|}{13.8} \\
\hline 4 & 5,7 & \multicolumn{3}{|c|}{11.9} \\
\hline 5 & 4,8 & \multicolumn{3}{|c|}{13.2} \\
\hline 6 & 1,11 & \multicolumn{3}{|c|}{14} \\
\hline 7 & 2 & \multicolumn{3}{|c|}{7.3} \\
\hline & Total & \multicolumn{3}{|c|}{80.7} \\
\hline & $\%$ of utilization of 14 day interval time & $(13.8 / 14)=$ & 99 & $\%$ \\
\hline & Time saving (compared to by turn) & $(13.8 / 80.7)=$ & 41 & $\%$ \\
\hline \multicolumn{2}{|c|}{ Canal Capacity(l/sec) } & $7 \times 116$ & 812 & l/s \\
\hline & Capacity utilization (compared to 1508 I/s by turn) & $(812 / 1508)=$ & 54 & $\%$ \\
\hline & Capacity saving (compared to by turn of " 13 x 116 l/s ") & & 46 & $\%$ \\
\hline
\end{tabular}

\section{CONCLUSIONS AND RECOMMENDATIONS}

It has been demonstrated that zero-one optimization techniques such as that used in this model was an attractive alternative for solving water allocation problem with complex network system. Model verification is tested by comparing its validity with other published models. It is concluded that the developed model offers many advantage over Suryavanshi and Reddy (1985) model for water allocation between various users. The suitability of the model for application to solve real water allocation problems is demonstrated with various cases and conditions using examples from actual field conditions in the Gezira scheme-Sudan. The developed model is a user-friendly tool and is capable of simulating an existing tertiary unit to investigate if it can be operated under an arranged demand schedule and the level of service that can be achieved.

The model can be used to analyze various water allocation problems underwater scarce conditions. The developed model is highly useful to water managers and professionals in making decisions for allocating water among user sectors. The use of such kinds of models/tools will increase with increased demand and pressure on the limited water resources.

The model may be further improved by incorporating other possible objectives of allocating water to different outlets by including equitable allocation, water quality aspects in relation to its use, sharing of benefit among the competing users, etc. 
The present model is limited to allowing users to demand duration and identical discharges. In future work, the model presented here need to be made more generic allowing different users to demand different discharges as well as durations. This scheduling and irrigation water allocation approach is only appropriate for irrigation systems where schedules for irrigation intervals are prepared in advance with users submitting requests (water order or indent) beforehand (as the case of the studied upstream control of Gezira). If the system is operated on the basis of users continuously submitting requests (downstream control) and irrigation authorities servicing those requests subject to certain constraints, such an arrangement then it is recommended to employ the queuing theories. The stochastic nature of model variables, water availability and demand and other aspects need to be taken into consideration in further development of the model.

\section{REFERENCES}

Ahmed M.A 1986 Evaluation of Performance of on-farm irrigation in Gezira Scheme Msc Thesis University of Gezira.

Anderson, R. L. and Maass, A., 1971 A simulations of Irrigation Systems: The Effect of Water Supply and Operation Rules on Production and Income on Irrigated Farms. U.S. Dept. Agric. Tech. Bull. 1431. Washington, D.C.

Anwar, A.A., Clarke, D., 2001.Irrigation scheduling using mixed-integer linear programming. J. of Irrigation and Drainage Engineering, ASCE 127 (2), 63-69.

Anwar, A. A. Clarke D, de Vries, T. 2005 Channel capacity under arranged demand irrigation Agricultural Water Management 82 (2006) 148-160

Bellostas, JM., 1994. Application of Linear Programming Models to Irrigation Water Delivery Models, Proceedings of the FAO Export Consultation, Food and Agriculture Organization of the United Nations, Rome, 155-164.

Brower, L. A. and Buchheimn J. F., 1982, An Irrigation District Computerized Water Management System. Proceeding of the Ninth Technical Conference of US
Committee of Irrigation, Drainage and Flood Control, Jackstones, Missouri

Farbrother, H.G., 1975. Water Requirements of Gezira and Managil Technical Notes on Water Use No. 2, Gezira Research station / FAO, wad Medani, Sudan.

Clement, R.,1966. Calcul des debits dans les reseaux d'irrigation fonctionant a la demand. Houille Blanche 5, 533-575.

Clemmens, A.J., 1986. Canal capacities for demand under surface irrigation. J. Irrigation. Drain. Eng., ASCE 112 (4), 331-347.

de Vries, T.T., Anwar, A.A., 2004. Irrigation scheduling., I. Integer programming approach. J. Irrigat. Drain. Eng., ASCE 130 (1), 9-16.

Matanga, G.B., and Marino, J.R. 1979b. Irrigation Planning, 2: Water Allocatin for leaching and Irrigation Purposes. Water Resour. Res. 15(3):675-678.

Monserrat, J., Poch, R., Colomer, M.A., Mora, F., 2004. Analysis of Clement's first formula for irrigation distribution networks. J.Irrigat. Drain. Eng., ASCE 130 (2), 99-105

Rajput, T.B.S., and Michael, A.M., 1989. Scheduling of Canal Deliveries, I : Development of an Irrigation Canal Scheduling Model. J. Irrigation. And Power (Central Board of Irrigation, India), 46(2):23-39.

Suryavanshi A.R. and Reddy A.M., 1985. Optimal Operation Schedule of Irrigation Distribution Systems. Agricultural Water Management 12 (1986) 23 - 30.

Wang, Z., Reddy, R., and Feyen, J., 1994 Improved 0-1 programming model for optimal flow scheduling in irrigation canals. Irrigation and Drainage Systems 9:105-116.

Yoo, K.H., and Bush, J.R., 1985, least Cost Planning of Irrigation System, Journal of ASCA, Vol. 111, No .4, Dec. 1985.

Zhenmin, Z., 1994. Optimization of Water Allocation in Canal Systems of chenGia Irrigation Area. In: Irrigation Water Delivery Models, Proceedings of the FAO Export Consultation, Food and Agriculture Organization of the United Nations, Rome, 165-172. 